\title{
Burnout: an emerging occupational health problem
}

\author{
PV De Silva ${ }^{1,}$ CG Hewage ${ }^{2}$, P Fonseka ${ }^{3}$ \\ ${ }^{\prime}$ Department of Community Medicine, Faculty of Medicine, University of Ruhuna, ${ }^{2}$ Department of Psychiatry, \\ Faculty of Medicine, ${ }^{3}$ Vsiting Professor, Department of Community Medicine, Faculty of Medical Sciences, \\ University of Sri Jayawardenapura.
}

e-mail address of the corresponding author,Dr.PV De Silva: pvijithadesilva123@yahoo.com

\section{Introduction}

Occupational health was a neglected area, both in developed and developing world. While $50 \%$ of workers in developed countries have access to occupational health services only $5-10 \%$ of workers have access to such services. Current advancement of the technology and identification of occupational risk factors in epidemiology has contributed to significant reduction of the physical occupational health problems in the world. However, due to increase demands of the jobs, stress related mental health problems are increasing rapidly. The working environment could be an important contributor to mental ill health and well-being of the worker. It is reported that mental ill health is the second largest work related illness after musculoskeletal disorders ${ }^{1}$. About three decades ago, a new disease entity called "Burnout" was described in the western world. Since then, a large number of scientists have defined and extensively studied about this concept.

\section{What is burnout?}

Frendenberger ${ }^{2}$ was the first person who identified 'burnout'. He described it as a feeling of failure and being worn out. Edelwich and Brodsky ${ }^{3}$ defined burnout as a progressive loss of idealism, energy and purpose. Pines and Aronson ${ }^{4}$ defined it as a state of physical emotional and mental exhaustion. Sarros and Densten ${ }^{5}$ described burnout as a maladaptive coping mechanism to working conditions that are stressful, demanding or lacking sufficient challenge and recognition.

The most commonly accepted definition came from Maslach $^{6}$ who described burnout as a multidimensional condition comprising (i) emotional exhaustion, (ii) depersonalization and (iii) reduced personnel accomplishment that can occur among individuals who do "People Work of some kind". Maslach ${ }^{7}$ further described burnout as a psychological process that begins when human service professionals are overwhelmed with the unexpected and unbearable stressful aspects of the job that frustrate their efforts to make a positive impact on others.

According to Maslach ${ }^{7}$, continued frustrating events may lead these professionals to feel emotionally exhausted and lacking the energy to face another day. To cope, they may detach themselves psychologically and emotionally, 'depersonalizing' those they serve as a means of distancing themselves from further stress laden situations. Over time these professionals may begin to develop an attitude of cold indifference to the needs of others, which may ultimately lead to a sense of reduced personal accomplishment, defined as feelings of incompetence and a sense of being unsuccessful in work related achievements.

Although burnout was first described as a very vague concept, now it is widely accepted as a psychological syndrome in response to chronic interpersonal stressors of the job. Now burnout is categorized under the problems related to lifemanagement difficulty, with the code z73.0 in the ICD-10 classification.

Further research has confirmed Maslach's theory that burnout is more prevalent among human service professionals such as nurses ${ }^{8}$, teachers ${ }^{9,}{ }^{10}$, social workers and mental health workers ${ }^{11}$.

Pines and Aronson ${ }^{12}$, described the reasons for high prevalence of burnout among human service professions. According to them, most individuals entering human service professions are motivated to 
do so by a desire to work with people and to make significant contributions to the lives of those they serve. These human service professionals have high expectations that they will succeed in their efforts to help others. If they failed in achieving this expectation, that sets the stage to potential burnout.

\section{Causes of burnout}

Causes of burnout can be categorized mainly into three groups: personal characteristics, job characteristics and organizational characteristics. On the currently available evidence, organizational characteristics have more profound effect on burnout, compared to personal and job characteristics $^{13}$. Demographic factors, lack of social support and high expectations of the job have been described as personal characteristics. Job characteristics include role conflict, role overload, role ambiguity and poor interpersonal relations. Job context, contingency and non-contingency of outcomes were observed as organizational characteristics $^{14}$. According to Albee ${ }^{15}$, burnout is associated with over work, under appreciation, confusion about expectations and priorities, anxiety over job security and over commitment for responsibilities.

\section{Signs and symptoms of burnout}

Derobbio and Iwanick $^{16}$ have listed anxiety, boredom, anger, cynicism, betrayal, depression, fatigue, frustration, resentment towards others, substance abuse, psychosomatic symptoms, mental and family crisis and reduction in commitment as the features of burnout.

\section{Measurement of burnout}

There are two main study instruments for the measurement of burnout.

\section{Maslach Burnout Inventory (MBI)}

2. Burnout Measure (BM)

According to the Shaufeli et al. ${ }^{17}$, Maslach Burnout Inventory (MBI) is by far the most popular instrument to diagnose burnout throughout the world. More than $90 \%$ of scientific publications and dissertations on burnout are based on the MBI. It has
22 items and can be used as a self-administered questionnaire.

The next most widely used instrument is Burnout Measure by Pines and Aronson ${ }^{18}$. This is used in about $5 \%$ of burnout studies. The BM is an internally consistent questionnaire, which assesses the individual's level of physical, emotional and mental exhaustion.

\section{Maslach Burnout Inventory (MBI)}

MBI was developed in 1980 to identify burnout among human service professionals. During the last 25 years it has been translated into several languages and used worldwide to measure burnout in different occupational settings. Later, minor modifications were made to the original MBI. Following these initial modifications, two new inventories were developed namely MBIEducators Survey (MBI-ES) to assess the educators' burnout and MBI- General Survey (MBI-GS) to assess the burnout among the workers in occupations other than human services. The original MBI was renamed as MBI-Human Services Survey (MBI-HSS).

All three MBI surveys address the three general scales;

(i) Emotional exhaustion - Feelings of being emotionally overextended and exhausted by one's work.

(ii) Depersonalization - An unfeeling and impersonal response towards recipients of one's service.

(iii) Personal accomplishment - Feeling of competence and successful achievement in one's work.

A number of studies done in different settings worldwide confirmed the validity and reliability of the MBI-ES. Iwanicki and Schwab ${ }^{19}$ studied 469 Massachusetts teachers and reported a Cronbach's alpha estimates of 0.90 for emotional exhaustion, 0.76 for depersonalization and 0.76 for personal accomplishment. Gold ${ }^{20}$ in his study of burnout among 462 California teachers reported Cronbach's alpha estimates of 0.88 for emotional exhaustion, 0.74 for depersonalization and 0.72 for personal accomplishment. One study assessed the 
construction validity of the MBI-ES using a sample of 750 Australian post primary (high school) teachers. This study confirmed the three factor structure and showed the inventory to be a reliable one ${ }^{21}$. Shaufeli et $a l^{17}$ studied the clinical validity of the MBI. They compared the findings of MBI with the diagnosis by a psychiatrist who used the criteria of 'work related neurasthenia' for the clinical diagnosis of burnout. By the results of this study they confirmed the validity of the MBI. Further, they were able to partly differentiate other mental disorders such as anxiety and depression from burnout.

\section{Prevalence of burnout}

Most of the studies on burnout had been carried out in the developed countries and very few studies had been conducted outside US and Europe. A study conducted in Taiwan found that $26 \%$ of primary teachers had burnout ${ }^{22}$. Recently concluded study among the primary school teachers in the southern province of Sri Lanka found relatively less prevalence $(11.56 \%)$ of burnout. According to districts in the Southern Province in Sri Lanka, Galle district had the lowest prevalence $(9.60 \%)$ while Hambantota district had the highest prevalence $(15.78 \%)$ of burnout ${ }^{10}$. About one-third of Australian teachers and $5 \%$ to $20 \%$ of American teachers were found to have burnout ${ }^{9}$. Prevalence of burnout was found to be $59.2 \%$ among the Japanese public health nurses working in mental health services while the public health nurses working in other units had a slightly lesser prevalence $(51.5 \%)^{23}$.

\section{Consequences of burnout}

Absenteeism and attrition are the major negative outcomes of burnout. In addition, there is a strong association between burnout and low or diminished job satisfaction. Burnout was also found to be strongly associated with many other variables that are connected to job satisfaction such as low levels of life satisfaction, low levels of control and low levels of health ${ }^{14}$. All these factors collectively contribute to reduce the productivity of an employee.

\section{Conclusion}

Burnout is a grossly understudied phenomenon in developing countries including Sri Lanka. Its causes and consequences are complex and interrelated. It adversely affects the employees and the productivity of an organization. Therefore, both employers and employees should be aware of burnout. Measures should be introduced to minimise burnout among employees.

\section{References}

1. Glozier N. Mental ill health and fitness for work. Journal of Occupational and Environmental Medicine 2002; 59:714-20.

2. Freudenberger HJ. Staff burnout. Journal of Social Issues 1974; 30:159-65.

3. Edelwich J, Brodsky A. Burnout: Stages of disillusionment in the helping professions. New York: Human Sciences Press. 1980.

4. Pines A, Aronson E. Burnout: From tedium to personal growth. New York: Free Press. 1981.

5. Sarros JC, Densten IL. Undergraduate students stress and coping strategies. Higher Education Research and Development 1989; 8:47-57.

6. Maslach C. Measurement of experience burnout. Journal of Occupational Behaviour 1981; 2: 99-113.

7. Maslach, C. Burnout. The cost of caring. Englewood Cliffs, NJ: Prentice-Hall. 1982.

8. Pick D, Leiter MP. Nurses perceptions of the nature and causes of burnout. Canadian Journal of Nursing Research 1991; 23: 33-48.

9. Demirel Y, Guler N, Thoktamis A, Ozdemir D, et al. Burnout among high school teachers in Turkey. Middle East Journal of Family Medicine 2005; 3 : 3.

10. De Silva PV. Burnout and other occupational health problems of female primary school teachers in the Southern Province of Sri Lanka. Thesis. Library, Post Graduate Institute of Medicine Colombo, 2007.

11. Pines A, Kafry D. Occupational tedium in the social services. Social Work 1978; 23: 499-507.

12. Pines A, Aronson E. Career burnout: causes and cures. New York: Free Press. 1988. 
13. Leiter MP, Maslach C. The impact of interpersonal environment on burnout and organizational commitment. Journal of Organizational behaviour 1988; 9 (4): 297-308

14. Cordes CL, Dougherty TW. A review and an integration of research on job burnout. Academy of Management Review 1993; 18: 621-56.

15. Albee GW. Commentary on prevention and counselling psychology. The Counselling Psychologist 2000; 28: 845-53.

16. Derobbio R, Iwanicki E. Factors accounting for burnout among secondary school teachers. Paper presented at the Annual Conference of the American Educational Research Association, New York. 1996.

17. Shaufeli B, Baker AB, Hoogduin K, Schaap CAS, et al. On the clinical validity of the maslach burnout inventory and the burnout measure. Psychology and Health, 2001; 16: 565-82.

18. Pines A, Aronson E. Burnout: From tedium to personal growth. New York: Free Press. 1981.
19. Iwanicki EF, Schwab RL. A cross-validational study of the Maslach Burnout Inventory. Educational and Psychological Measurement 1981; 41: 1167-74.

20. Gold Y. The relationship of six personal and life history variables to standing on three dimensions of the Maslach burnout Inventory in a sample of elementary and junior high school teachers. Educational and Psychological Measurement 1985; 45: 377-87.

21. Maslach C, Jackson S, Leiter M. Maslach Burnout Inventory Manual. $3^{\text {rd }}$ edition, California, Consulting Psychologist Press. 1996.

22. Kyriacou C, Chien P. Teachers stress in Taiwanese primary schools. Journal of Educational Enquiry 2004; 5: $2-5$.

23. Imai H, Nakao H, Nakagi Y, Niwata S, et al. Prevalence of burnout among public health nurses in charge of maternal health services and emergency care systems in Japan. Environmental Health and Preventive Medicine 2006; 11: 286-91. 